\title{
POR MÉMORIAS DO FUTURO: AS PONTENCIALIDADES DO PATRIMÔNIO PARA O DESENVOLVIMENTO LOCAL NA COMUNIDADE QUILOMBOLA DO BUIEIÉ
}

\author{
FOR THE MOMENTS OF THE FUTURE; THE CHARACTERISTICS OF THE \\ HERITAGE FOR LOCAL DEVELOPMENT IN THE KILOMBOLA COMMUNITY OF \\ BUIEIÉ
}

\begin{abstract}
A. C. S. S. $\mathrm{CIRO}^{1, *}$
1Universidade Federal de Viçosa, Departamento de História. Mestranda Pelo Programa de PósGraduação Profissional em História Patrimônio Cultural Paisagens e Cidadania, Brasil
\end{abstract}

ARTICLE INFO

Article history:

Received 2018-04-13

Accepted 2018-04-30

Available online 2018-05-02
Palavras-chave: Memória. Patrimônio Imaterial. Quilombo. Cidadania. Buieié-Viçosa MG.

Keywords; Memory. Intangible Assets. Quilombo. Cidadania. Buieié-Viçosa MG.

${ }^{*}$ Autor correspondente:

E-mail: amanda.ciro@ufv.br

RESUMO. O presente trabalho pretende fazer uma discussão sobre Patrimônio Imaterial nas comunidades quilombolas, tomando como objeto de estudo a comunidade quilombola do Buieié em Viçosa MG. Trazendo reflexões recentes no campo do patrimônio visto a aflorada busca por 'memórias e patrimônios em desaparecimento' e algumas relações que envolvem políticas públicas patrimoniais, instituições e comunidades. A discussão perpassará no campo da memória e História suas relações com o patrimônio. Como também aborda uma sugestão de ação metodológica no campo da Educação Patrimonial, que visa um trabalho endógeno a comunidade detentora, partindo de suas necessidades para uma apropriação cultural e da prerrogativa que a gestão do patrimônio cultural deve ser feita o mais próximo possível de seus detentores e criadores.

ABSTRACT. The present work intends to make a discussion about Intangible Heritage in the quilombola communities, taking as object of study the quilombola community of Buieié in Viçosa MG. Bringing recent reflections in the field of patrimony since the search for 'disappearing memories and patrimonies' and some relationships that involve patrimonial public policies, institutions and communities. The discussion will pervade in the field of memory and History its relations with the patrimony. suggestion of methodological action in the field of Patrimonial Education, which aims at an endogenous work to the holding community, starting from its needs for a cultural appropriation and the prerogative that the management of cultural heritage should be made as close as possible to its owners and creators.

\section{INTRODUÇÃO}

Nos últimos anos observamos o aflorar da febre de patrimonialização, grandes ou pequenas as sociedades têm se esforçado para eleger e salvaguardar seu patrimônio cultural como suas memórias. Presenciamos o despertar de muitas memórias: a do negro a da mulher, da cidade do bairro da comunidade uma multiplicação infinita de vozes em busca de memórias adormecidas, de patrimônios não legitimados institucionalmente a crescente verticalização das cidades e a impactante 
individualização do homem na sociedade cada vez mais interagido com a tecnologia do que com seus pares faz nascer na sociedade contemporânea a sede por memórias, tradições, elos que ressignificam e fortificam a vida em sociedade. Adjunto a insurgência das políticas públicas patrimoniais e de gestão do patrimônio cultural e de memórias como forma de captação de recursos para as esferas governamentais.

Este trabalho é fruto do início de minhas pesquisas e reflexões para meu trabalho de obtenção para título em mestre em história no Programa de Pós-Graduação Profissional em Patrimônio Cultural Paisagens e Cidadania, da Universidade Federal de Viçosa (UFV), intitulado Memória, Identidade e Cidadania: Entre Reflexões e diálogos com a comunidade quilombola do Buieié Viçosa MG, em condição de desenvolvimento desde 2017 ao presente ano. Neste momento apresentamos a orientação teórica e metodológica que norteará nosso trabalho, apresentando novos caminhos e possibilidades a serem discutidas dentro da temática do patrimônio imaterial.

Em meio a essa efervescência pelo passado seus significados o que Meneses (1992), delimita como revivals, estão pessoas envolvidas, comunidades inteiras dotadas de sentimentos, identidades formas de vida únicas e diferenciadas. Mas nos indagamos, qual é o lugar das pessoas envolvidas, em meio á tantos decretos e títulos que elegem memórias e patrimônios muitas das vezes sem dar voz aos próprios detentores?

Hussen (2000) fala de uma guinada transnacional dos estudos de memória nos países sulamericanos influenciando claramente a política nacional os processos judiciais comissões da verdade e em outros seguimentos sociais, destacando os usos e abusos destas memórias correlacionando com o discurso dos direitos humanos internacionais, no qual demarca a insurgência de um novo discurso de direitos humanos que emerge paralelo ao discurso de memória em 1980. O autor frisa a necessidade de novos estudos que correlacionem o discurso da memória com a história desenvolvimento da legislação e da prática dos direitos humanos que se acelerou com a introdução comercial da internet. A relevância do tema em expansão tanto na prática de instituições culturais quanto na mídia, se deve às constantes transformações das novas tecnologias de informação, imediatismo e individualismo, que conduzem a sociedade a uma instabilidade, buscando na "memória" resignificações afetivas para as sociedades: "Fala-se tanto de memória porque ela não existe mais" 1

Observamos ainda tal busca por rememoração do passado em muitas cidades brasileiras, condicionadas por incentivos e políticas públicas patrimoniais, um exemplo claro é o ICMS cultural, Imposto Sobre Circulação de Mercadoria e Prestação de Serviços (ICMS), ou popularmente lei Robin Wood $^{2}$. Segundo informações da página oficial do IEPHA, o Instituto Estadual do Patrimônio Histórico e Artístico de Minas Gerais (IEPHA-MG) é um programa de incentivo à preservação do patrimônio cultural do Estado e das referências culturais, através de políticas públicas relevantes. Viçosa, por exemplo, destacou-se entre as cidades de sua região na pontuação ${ }^{3}$. Enfim que memórias estão sendo, buscadas qual é o patrimônio que está sendo valorizado, e divulgado como sendo um bem a sociedade viçosense? Isto se reproduz em todas as cidades de Minas gerais, como em todo país.

1 NORA, Pierre. Entre memória e história: a problemática dos lugares. Projeto História, São Paulo (10), dez. 1993 , p. 7.

2 Atividade permanente do estado iniciada em 1996, a Lei Robin Hood define os critérios de distribuição dos recursos do ICMS/IPIexportação para os municípios de Minas Gerais com os objetivos de melhorar a distribuição da receita arrecadada com o imposto e promover o desenvolvimento de políticas públicas em âmbito municipal.

3 Informações retiradas no site oficial http://iepha.mg.gov.br/index.php/comunicacao/sala-de-imprensa 
Segundo Mauricio Abreu (2014), em Sobre a memória das cidades; a cidade é uma das aderências que ligam indivíduos, famílias, e grupos sociais entre si, mas a cidade não é um coletivo de vivencias homogêneas. Para definirmos a memória de uma cidade nossa categoria de análise não poderia ser a população, coexistem em uma cidade em qualquer momento do tempo inúmeras memórias coletivas, no momento em que se eternizam em registros permanentes não se perde o caráter especifico de sua vinculação ao grupo ou classe que a produziu, mas há algo a mais para se considerar, nem todas memórias de uma cidade conseguiram ser registradas, muitas se perderam no tempo, o que faz com que os vestígios do passado que subsistiram na paisagem, na vida quotidiana ou nas instituições de memória sejam apenas fragmentos das memórias coletivas que a cidade produziu. Estes muitas vezes ligados as estruturas de poder, fazendo com que memórias de grupos sociais mais frágeis se percam com o tempo, dar voz á estas memórias desvinculadas das estruturas de poder é uma tarefa necessária e urgente.

Segundo Abreu (2014), é na preocupação constante em se registrar as memórias coletivas presentes no cotidiano atual da cidade, de uma comunidade, poderemos relembrar o passado, eternizar o presente e garantir às gerações futuras um lastro de memória fundamental para a sua identidade. Tal ideia s complementa com o que Pollak (1989) afirma "que uma memória também que, ao definir o que é comum a um grupo e o que, o diferencia dos outros, fundamenta e reforça os sentimentos de pertencimento e as fronteiras socioculturais"4.

Assim como Gonçalves (1996) em Retórica da Perda destaca que o patrimônio cultural é feito de Ruínas, em sentido literal e metafórico, as narrativas construídas sejam pelas cidades, grupos, indivíduos e instituições de memória jamais conseguiram abranger uma totalidade coerente, é um processo interminável de apropriação e reconstrução de objetos, sempre em desaparecimento, em um interminável jogo entre fragmentos e totalidades, destruição e reconstrução, coerência e desintegração usado simbolicamente para que as pessoas se vejam e se identifiquem com a nação, como uma entidade a ser protegida e preservada.

O campo do patrimônio é e será sempre área de conflitos, onde os arquitetos da memória que hoje configuram as instituições e gestores da cultura sempre investiram estratégias para construir e usufruir de uma memória dita das comunidades, das cidades do país criando e recriando histórias nacionais, identidades nacionais. Mas bem sabemos da nossa multiplicidade de culturas como de memórias, assim são necessários trabalhos que estimulem investigações que estimulem e permitam pensar as ações e características da administração pública através do viés dos indivíduos das comunidades ${ }^{5}$.

Afinal, quando lidamos com patrimônio cultural imaterial lidamos com o vivo, com o dinâmico e mutável, diferentemente do patrimônio em pedra e cal não podemos engessar saberes práticas e formas de vida ou memórias. Assim como tudo que é vivo se transforma constantemente, o trato com tais fenômenos dessa natureza requer subsidiariedade do sujeito, devendo ser visto como um recurso para o desenvolvimento local. Isso vai de encontro com o que Le Goff ao argumentar que a memória, onde cresce história - a qual por sua vez a alimenta - procura salvar o passado para servir

4 POLLAK, Michael. Memória, esquecimento, silêncio. Estudos Históricos, Rio de Janeiro, vol. 2, n.3, 1989 , p.3.

5 CHUVA, Márcia Os arquitetos da memória: sociogênese das práticas de preservação do patrimônio cultural no Brasil (anos 1930-1940). Rio de Janeiro: Ed. da UFRJ, 2009. 
o presente e o futuro, devemos trabalhar de forma a que a memória coletiva sirva para a libertação e não para a servidão dos homens (LE GOFF, 1994, p. 525).

Este trabalho pretende realizar uma reflexão sobre a importância do fazer etnográfico em diálogo com as políticas públicas no âmbito do patrimônio cultural imaterial brasileiro, suas ações e reflexos dentro das comunidades, principalmente dentro das tradicionais, No nosso caso um quilombo como objeto de análise , o Buieié de Viçosa Minas Gerais, visamos compreender como e quando se situa a comunidade dentro dessas relações entre políticas públicas políticas patrimoniais, como é apropriação de seus habitantes de sua cultura e formas de vida que retratam códigos específicos dessa comunidade. Onde depreendemos o patrimônio como recurso para alcance de desenvolvimento cidadão, sendo um recurso não renovável e eminentemente transformável, reprodutível que se regenera. Assim acreditamos que se o compreendemos, delimitamos, trabalhamos e o valorizamos de acordo com as necessidades específicas de cada comunidade, ele se torna um rico recurso para o desenvolvimento local como um processo de domínio da mudança cultural, social, econômica, nutrindo suas raízes no patrimônio que se torna vivo e nutrido diariamente.

O patrimônio cultural Imaterial constitui-se como autêntico, vivo, constantemente recriado e reexperimentado qual querem transforma em registro mnemotécnico, exposto a volatilidade do mundo moderno e globalização é ameaçado constantemente. É necessário que o vejamos mais além do que apenas como bem que se quer salvaguardar, requer que nós o vejamos como cultura transmitida perpetuada através da oralidade encontrando na mente humana o seu principal repositório. Devendo ser valorizado como elemento essencial à existência, às identidades coletivas, crenças, tradições e costumes de distintos grupos humanos. Nosso desafio é enxergar o Homem tradicional como patrimônio vivo que devendo ser trabalhado, instrumentalizado para que o próprio coloque em prática ações que visem o desenvolvimento local da comunidade. Se faz necessário cada vez mais dentro do campo de estudo do patrimônio, traçar conexões entre os conceitos PatrimônioEducação- cidadania e Comunidades, conexões não apenas epistemológicas, mais conexões vivas que geram e capacitam ações para atender cada vez mais o USO SOCIAL desse patrimônio, seja qual for sua natureza, material ou imaterial, como argumenta Horta é necessário atribuir sentidos.

Atribuir sentidos é compreender a identidade humana e perceber que somos indivíduos históricos e culturalmente elaborados. E aceitar que somos um fragmento do mundo no qual vivemos e do planeta que habitamos - um conjunto formado pela comunidade e sociedade e suas interações. Somos múltiplos com uma complexidade indecifrável, imersos em uma infinidade e culturas e de identidades. É preciso que percebamos a nossa individualidade na heterogeneidade das relações humanas, em uma sociedade diversa e singular. Atribuir sentidos aos patrimônios é compreender a nossa condição humana e a diversidade de explicações. É, sobretudo compreendermos uns aos outros, realizar a comunicação humana e colocar-se no lugar do outro; uma difícil tarefa em uma sociedade individualista, que não percebe a existência do outro, que o rejeita e o reduz ao nada. Logo, é preciso autoavaliação e exame. Atribuir sentidos é aceitar a incerteza e o inesperado. Então, temos de ser fortes e não nos desencorajarmos diante dos desafios. É preciso ter consciência de nossa condição planetária, de um mundo globalizado, imerso em informações velozes, que não conseguimos processar e organizar (HORTA, 2017, p. 15). 
Ávila (2014) aponta que as políticas públicas do patrimônio cultural caminharam paralelas com o marco legal dos direitos destas populações negras, como a Carta Constitucional de 1988, na qual os grupos autoidentificados como remanescentes de quilombos passaram a ser amparados pela legislação no que diz respeito à titulação de suas terras e reconhecimento de direitos culturais, previstos nos artigos 215 e 216. A respeito do reconhecimento das referências culturais afrodescendentes, a Constituição prevê em seu artigo 215 a proteção das manifestações culturais afro-brasileiras e estabelece, no $5^{\circ}$ parágrafo do artigo 216 , que "ficam tombados todos os documentos e os sítios detentores de reminiscências históricas dos antigos quilombos". Ao mesmo tempo, o artigo 68 do Ato das Disposições Constitucionais Transitórias prevê que o estado reconhecerá a propriedade definitiva das terras que estejam ocupadas pelos remanescentes das comunidades dos quilombos.

Quanto às leis institucionalizadas e as Formas de proteção do patrimônio cultural imaterial no Brasil destaca se que desde 1930, já se abordava questão do patrimônio Imaterial com Mario de Andrade, que já considera as manifestações culturais como portadores de referência a identidade, a ação, a memória dos diferentes povos formadores da sociedade brasileira. Porém, somente em 4 de agosto de 2000 com o decreto $3.551 / 2000$, foi institucionalizado um recurso de reconhecimento e valorização do patrimônio imaterial.

Bartz (2014) destaca a clara disparidade do discurso dos últimos anos de uma valorização do Patrimônio Cultural e Imaterial, como das iniciativas em patrimonializar os saberes-fazeres e manifestações culturais em contrapartida a participação efetiva das comunidades envolvidas e a sonegação de direitos básicos de bem estar social aos mesmos, questiona os impactos sofridos, os benefícios e interesses envolvidos por detrás destes processos, e a característica totalmente exógena destes processos em relação as comunidades.

Segundo Cristiane Ávila (2014), essas ações políticas tinham por objetivo estabelecer um elo entre as comunidades e as instituições governamentais, mas o que se faz de fato é a perpetuação da condição histórica de dependência e de 'aliciamento' das condições materiais. A autora reforça ainda que acredita em um trabalho conjunto com vários profissionais que envolva desde historiadores, economistas, médicos, enfermeiros, educadores, atuando com a ênfase em Educação Patrimonial, sendo para ela um processo de tornar os próprios moradores aptos para reestruturar a comunidade, dando os subsídios necessários para o que ela coloca como uma 'autonomia e a condição cidadã.'

Acreditamos assim que nosso trabalho, que visa traçar um olhar sobre o patrimônio cultural partindo de uma perspectiva endógena, na comunidade do Buieié, contribuirá para essa nova demanda em que o patrimônio é visto como recurso para se alcançar as potencialidades de uma comunidade, trabalhando o conceito de apropriação.

Para José Reginaldo Gonçalves (1996) em Retórica da Perda, a noção de "apropriação" é um termo primordial nos discursos do Patrimônio Cultural, destaca que apropriar-se de algo implica uma atitude de poder, de controle sobre aquilo que é o objeto de apropriação, implicando também um processo de identificação, onde um conjunto de diferenças é transformado em identidade, ele complementa que isto como sendo tentativa de restabelecer, defender ou dar continuidade do que define a identidade e a memória, um esforço para garantir autenticidade e restaurar 'um sentimento de ser.

Estudiosos como Vaz (2014), destaca que a partir da mudança de perspectivas no texto da Constituição Federal de 1988, o Instituto do Patrimônio Histórico e Artístico Nacional (IPHAN), 
responsável pela proteção e salvaguarda do patrimônio cultural no Brasil, necessitou agir para atender às novas demandas que nasceram com reconhecimento dos bens referenciais da matriz afrodescendente, dentre os quais aqueles relativos às comunidades quilombolas. Assim, o tombamento e, a partir do ano 2000 , o registro, instrumentos da política de patrimônio nacional de uso privativo do IPHAN, passaram a ser acionados como forma de reconhecimento, proteção e salvaguarda desses bens, a autora destaca muitos conflitos entre os decretos, leis e as práticas efetivas, destacando que ainda hoje o reconhecimento e valorização de bens imateriais, materiais está vinculado á valores históricos, estéticos e documentais 'consagrados'.

Devemos lembrar que pós anos 2000, quando passa a valer a autodefinição de comunidades negras como quilombos ação suficiente para receber o título pela Fundação Palmares, houve uma ampliação no conceito de patrimônio cultural paralelamente, como depreende. Assim, operou-se a ressemantização dos termos quilombo e quilombola que, a partir de uma perspectiva dinâmica, considerando a perspectiva destas comunidades, grupos atualmente, não os tomando mais como resquícios ou fragmentos de um passado congelado, intacto. Como foi definido pelo Grupo de Trabalho sobre Comunidades Negras Rurais da Associação Brasileira de Antropologia.

Contemporaneamente, portanto, o termo quilombo não se refere a resíduos ou resquícios arqueológicos de ocupação temporal ou de comprovação biológica. Também não se trata de grupos isolados ou de uma população estritamente homogênea. Da mesma forma, nem sempre foram constituídos a partir de movimentos insurrecionais ou rebelados, mas, sobretudo, consistem em grupos que desenvolveram práticas cotidianas de resistência na manutenção e reprodução de seus modos de vida característicos e na consolidação de um território próprio (ABANT, 1994, p. 1).

A autora Beatriz Vaz (2014), nos instiga a refletir sobre as questões envolvidas no reconhecimento dos quilombos como parte do patrimônio cultural nacional. Vaz (2014) destaca que o tombamento de apenas dois quilombos históricos e o latente silêncio nos dossiês de registro sobre os quilombos contemporâneos indicam a manutenção de uma visão passadista de quilombo, reflete no não reconhecimento da atualidade da luta quilombola pelo reconhecimento dos direitos coletivos dos grupos. Acrescenta que a perspectiva adotada pelo órgão, IPHAN, a cultura é concebida de forma fragmentada, tanto pela separação de suas dimensões "materiais" e "imateriais" como pela categorização dos bens em diferentes livros de tombo - no caso do patrimônio imaterial, a partir das categorias: "saberes", "formas de expressão", "celebrações" e "lugares", segundo ela isto coloca obstáculos para o reconhecimento do patrimônio cultural de comunidades quilombolas, e faz com que muitos dos saberes e práticas sejam desconsiderados, uma vez que o vínculo com o território, estruturador de diversas relações, não é contemplado pelas políticas patrimoniais.

Acompanhando o pensamento do museólogo Varine (2012), precisamos sair da teoria para a prática, devemos lembrar a todo instante, como pesquisadores, gestores do patrimônio que o concreto é a vida cotidiana, que o patrimônio não está, e não deve estar separado da vida cotidiana. Este como um recurso do desenvolvimento local, não pode ser visto fora dos ritmos da sociedade local, pois serve inicialmente para alguma coisa nas mãos de seus detentores habituais. Nós como estudiosos, teóricos da área como também as instituições de memória, devemos nos posicionar apenas como mediadores, gerindo pela margem, preocupando mais em apontar caminhos do que chancelando soluções. 


\section{A COMUNIDADE dO BUIEIÉ, VIÇOSA MINAS GERAIS, E A PROPOSTA METOdOLÓGICA INTERATIVA, O PATRIMÔNIO COMO RECURSO DE DESENVOLVIMENTO LOCAL}

A Comunidade do Buieié se localiza na cidade de Viçosa MG, cerca de 15 a $20 \mathrm{~km}$ do chamado centro histórico da cidade, uma população composta majoritariamente por negros que construíram narrativas de sua história local atrelada aos ex escravos que viveram na região da cidade que era chamada de Santa Rita do turvo.

Segundo os estudos de Fernando Costa ( 2015) em sua tese de doutoramento aproximadamente $57,17 \%$ de toda a riqueza inventariada em Santa Rita do Turvo, entre 1850/79, estava alocada em cativos. O autor acrescenta que neste cenário, a inversão de recursos em escravos, mão de obra fundamental mesmo para uma localidade desta natureza, mostrou-se a principal estratégia, e aquela possível, de alocação de recursos. Dessa forma, mesmo em uma região carente de dinamismo econômico, distante dos centros administrativos, populacionais e produtivos, o vigor da escravidão brasileira fica indubitavelmente expresso em santa Rita do Turvo atual Cidade de Viçosa. O que atesta a real e significativa presença de escravos como a de afrodescendentes que compartilham memórias da escravidão e seus momentos posteriores na nossa região.

Segundo dados coletados e analisados no arquivo da Secretaria Municipal de Saúde. Constatamos que oficialmente vivem na comunidade cerca de 135 famílias com um total de 390 pessoas, sendo 80 idosos, e 72 crianças de 0 a 14 anos e o restante adultos jovens. Aferimos que a maioria da população é jovem, talvez ai uma justificativa para voltarmos o olhar para essa comunidade tradicional que dentro do tempo e espaço sofre transformações contínuas. A história da comunidade se respalda em uma serie de mitos de origem atreladas a escravidão, que com a morte dos seus anciões se perde a cada ano que se passa.

A professora Neide Maria de Almeida Pinto do Departamento de Economia Doméstica da Universidade Federal de Viçosa, MG, Doutora em Ciências Sociais em seu artigo Família, identidade e vínculos no meio rural: a comunidade negra do Buieié a comunidade revelou um contexto híbrido, indicando tradicionalismos e processos de mudança social em curso. Os vínculos de parentesco e de amizade na comunidade constituíram-se em fortes elementos explicativos para se compreender as estratégias de reprodução social das famílias e para compreender o forte sentimento de pertencimento ao lugar.

Estes corroboraram para a estruturação de uma identidade territorial, a partir das relações e sentimentos construídos ao longo do tempo. o território para a comunidade ser tomado como um mito de origem, erguido através da imagem das terras por eles herdadas, as quais lhes permitem se reconhecer como parte de um todo, de uma "grande família" principalmente entre os mais velhos. A terra expõe a história de suas vidas, que é também a história de seus ancestrais e quando falam desse passado, a memória os remetia às raízes histórias de um período de luta e de sofrimento. Para os idosos a terra é vista como um lugar a ser preservado, mais do que unicamente um meio de produção, moradia, não trata se de qualquer terra, mas a terra na qual mantiveram uma relativa autonomia cultural, social e histórica.

Observamos em nossas visitas de campo que a comunidade quilombola do Buieié não atende aos quesitos pelo IPHAN segundo decreto de 1998, que delimita como sendo quilombos as comunidades autoexcluídas da sociedade nacional durante o período colonial até a abolição da 
escravatura, formados originalmente por negros escravos fugidos das áreas urbanas ou rurais onde existiam práticas de exploração escravista (IPHAN, 1998, p. 7), uma vez que a estética de urbanização já se modificou e não há documentação histórica que ateste arqueologicamente sua relação com os escravos que viveram nesta região. Tal decreto não considerava concepção contemporânea de quilombo, baseada não na origem desse, mas na forma presente como seus membros se identificam que é o caso da comunidade do Buieié que recebeu o título pela Fundação Palmares em 10/12/2004.

De acordo com os apontamentos de Dalmo Vieira Filho, em seu verbete publicado pelo IPHAN, sobre o tombamento de quilombos: atualizando discussões sem data publicada, observamos que a comunidade do Buieié se encaixa no formato de núcleos formados até meados do século $\mathrm{XX}$, predominantemente por descendentes de escravos, como decorrência dos rearranjos sócio/econômico/culturais diretamente decorrentes da abolição da escravidão no Brasil' .

Mas enfim o que está em voga é a existência de uma comunidade tradicional, que formas e relações de vida que denotam sua ancestralidade, como saberes, formas de viver e se relacionar em entre si, comprova - se na comunidade através das conversas com os moradores - o que Giddens (2003) afirma sobre as sociedades tradicionais, que o passado é venerado e os símbolos são valorizados porque contém e perpetuam a experiência de gerações. Eles têm na 'tradição' um meio de lidar com o tempo e o espaço, inserindo qualquer atividade ou experiência particular na comunidade do passado, presente e futuro, os quais, por sua vez, são estruturados por práticas sociais recorrentes ${ }^{7}$.

A questão da oralidade, do relatar e contar as memórias e práticas de vida dessa sociedade se fazem muito presentes principalmente na população mais velha. Sabemos que nas sociedades tradicionais africanas as narrativas orais configuram os pilares de valores e as crenças transmitidas pela tradição e veneram o respeito ao legado ancestral da cultura e aos mais velhos que são vistos como livros vivos. Tal valor atribuído aos mitos e aos contos de formação da comunidade remonta a sua matriz africana:

A memória das antigas sociedades africanas se apoiava na transmissão continuada de histórias, contendo conhecimentos, princípios e valores que preservavam, entre outros, o sentido agregador enquanto família e vinculação à terra. Portanto, 0 ato de lembrar está na essência das tradições que sustentam a organização comunitária e formas de governar nessas sociedades (MACHADO, 2016, p 12).

Tais características são muito claras na comunidade, e atestamos nas conversas com moradores que ali nasceram se criaram e já quase completam um centenário de vida como o Sr. João Laurindo que relata se lembrar das casinhas de pau a pique de telhado de palha. Há várias formações sobre a formação e estruturação do bairro pelos moradores, mas todos atrelados a escravidão na região. Lucas Magno em seu trabalho Que Lugar é este? apresenta algumas entrevistas com os moradores da comunidade onde alguns relataram a história da comunidade. Vejamos há uma versão, contada inicialmente em conversas informais com antigos moradores, as terras foram compradas por uma ex-escrava, Maria Luiza do Carmo. Para efetuar a compra, essa

6 VIEIRA FILHO, Dalmo. Sobre o tombamento dos quilombos: atualizando a discussão. Brasília: Iphan, s.d.p 8.

7 GIDDENS, A. As Consequências da Modernidade. Oeiras, Celta Editora, 2003.p 18. 
senhora criava suínos para comercializar e, "com muita dificuldade", o dinheiro da venda desses animais possibilitou-a adquirir aquelas terras. Justificando a escolha, os moradores dizem que ${ }^{8}$ :

A sinhá era boa, não confiava nos brancos somente nos seus negros, dizia que se um dia caísse, só os seus negros a ajudariam, por isso vendeu as terras para sua cativa que era vó do João. Entrevistado 16, 86 anos, nascida e criada no Buieié, 2008.

A escrava que comprou as terras era afilhada da fazendeira. A escrava é avó do João e minha. Aí as terras foram sendo passadas para os filhos. Entrevistado 4, 87 anos, nascida e criada no Buieié, 2006.

Isso aqui é herança da minha avó Maria Luiza que engordava capado e só comia a barrigada, juntou dinheiro e comprou as terras e foi doando para os filhos e assim por diante, aí estamos aqui até hoje cuidando disso aqui (Entrevistado 14, 63 anos, nascido e criado no Buieié, 2006).

Na comunidade além da "oralidade" dos anciões encontramos ainda outras manifestações culturais que remontam a importância dos saberes tradicionais para a comunidade que com o passar dos anos perderam força segundo os próprios moradores como Tambores do Buieié, o Artesanato Local, trabalhos manuais com palha, taquara e diversos outros. Não podemos esquecer das Relações com as plantas Medicinais, saberes tradicionais que repassam as gerações. Em relatos informais os moradores mais velhos destacam o desinteresse dos mais jovens em aprender as práticas e saberes sendo necessário que seja feito algo pra apropriar estes jovens de sua cultura local.

É valido ressaltar que neste trabalho o intuito é trabalhar o patrimônio cultural imaterial desta comunidade, sabemos que o patrimônio cultural Imaterial constitui se como autêntico e espontâneo, vivo, constantemente recriado e reexperimentado está exposto á volatilidade do mundo moderno e globalização sendo ameaçado constantemente.

Mais que um bem que se quer salvaguardar, requer que nós o vejamos como cultura transmitida perpetuada através da oralidade encontrando na mente humana o seu principal repositório, assim deve ser valorizado como elemento essencial à existência, às identidades coletivas, crenças, tradições e costumes de distintos grupos humanos nosso desafio é enxergar o Homem tradicional como patrimônio vivo que deve ser trabalho, instrumentalizando o para que o próprio em sua comunidade trabalhe para o desenvolvimento local.

Nosso trabalho objetiva contribuir, usando da Educação Patrimonial informal dentro da comunidade, para a apropriação da cultura local dos moradores do Buieié, compactuando com a concepção de Santana (2012) ao apontar que, "os fragmentos do passado estão explícitos, nos espaços, nas ruas, nos saberes e fazeres de um povo que estes sendo importantes maneiras de conhecimento de sua história e das suas relações sociais", justifica esta tentativa de conhecer, identificar, divulgar estes fragmentos da comunidade Buieié, fazendo com que o passado seja uma força matriz, contribuindo para a afirmação da identidade desta comunidade no presente que tanto necessita estímulos e apoio social.

Relembrando que a comunidade não dispõe de assistência de saúde e de uma escola dentro da comunidade, e que grande parte da população é depende de estímulos e apoio social vindos do

8 MAGNO, Lucas. Que lugar é esse? Identidades e significados territoriais no bairro rural Buieié - Viçosa, MG. Monografia apresentada ao Curso de Geografia da Universidade Federal de Viçosa, 2008. 
governo como Bolsa Família segundo dados de arquivos da secretaria de saúde os quais analisamos no ano de 2017.

\section{METODOLOGIA}

Partimos da ideia que apropriar se de algo implica uma atitude de poder, de controle sobre aquilo que é o objeto de apropriação, implicando também um processo de identificação, onde um conjunto de diferenças é transformado em identidade uma tentativa de restabelecer, defender ou dar continuidade do que define a identidade e a memória, restaurando 'um sentimento de ser

Usaremos para isto o aporte metodológico da "história oral" para registros das memórias da comunidade. Para Thompson (1992), aprender a ouvir é uma habilidade humana fundamental e a história oral está aí para auxiliar tanto na compreensão do passado, como para criar memórias nacionais mais ricas, mas, sobretudo para nos ajudar a construir um futuro melhor, mais amável e mais democrático9. Acrescento ainda a metodologia cunhada por Varine (2012) em seu livro As Raízes do Futuro, o patrimônio a serviço do desenvolvimento loca/10, no qual o museólogo europeu delimita o que chama de "metodologia experiência interativa", onde por meio da observação participante e da interação com a comunidade, de acordo suas necessidades locais são traçados métodos e ações, onde todo trabalho é organizado em fichas temáticas, explicando o tipo de público, duração, objetivos e resultados. Para nossa ação na comunidade, planejamos a execução do nosso trabalho na seguinte configuração, é valido lembrar que este só foi proposto após um ano de interação com a própria comunidade na busca de atender e contemplar as necessidades de acordo com a realidade local do Buieié.

\section{ALGUNS APONTAMENTOS E RESULTADOS}

Identificamos três grupos a serem trabalhados na comunidade, os idosos recintos vivos da memória do local que precisam ser ouvidos e valorizados, os jovens mais dinâmicos que se preocupam muito com a falta de lazer e atividades dentro da comunidade e se envolvem ainda pouco com suas manifestações culturais, mas tem grande participação nos Tambores do Buieié como opção lazer e distração porém necessitam apropriar das memórias e manifestações culturais da comunidade, e a população de crianças que necessita aprender e criar vínculos com a identidade da comunidade como da matriz afrodescente. Assim planejamos o trabalho no seguinte formato de encontros na comunidade com grupos específicos separadamente, adultos, jovens e crianças.

Os encontros abordaram questões específicas identificadas de acordo com a necessidade identificada através da observação participante nas visitas de campo. Para os adultos os encontros aconteceram no café com memória no Buieié, com o formato de roda de conversa aberto para reflexão e diálogo entre os próprios moradores, alguns já foram realizados na primeira fase do nosso trabalho e os resultados obtidos foram muito satisfatórios; um momento de socialização entre os moradores como também um momento de troca e aprendizado entre eles.

Para as crianças estão sendo realizadas oficinas Raízes do Futuro com contação de histórias da cultura afro-brasileira que estimulam e valoriza a mesma, oficinas práticas que correlacionam e estimulem a história africana e afro-brasileira com a formação da comunidade onde

9 THOMPSON, Paul. A voz do passado. História Oral. Rio de Janeiro: Paz e Terra, 1992.

10 VARINE, Hugues de. As Raízes do Futuro: o patrimônio a serviço do desenvolvimento local. Porto Alegre: Medianiz, 2012. 
vivem, estimulando o sentimento de pertencimento e valorização da mesma. Para os Jovens programamos o cine memória com debates temáticos, esses encontros ainda não aconteceram, mas o objetivo é tratar temas contemporâneos correlacionados às culturas africana e afro-brasileira e à história de vida dos moradores da comunidade, mostrando a necessidade de se valorizar a identidade de ser morador do Buieié.

Ressaltamos, porém que toda a ação planejada pode e deve ser sempre modificada de acordo com a necessidade da comunidade, pois nosso objetivo é atuar como mediador, para que a própria comunidade trabalhe suas potencialidades, pois partimos da ideia defendia por Varine (2012) que seja material, imaterial, morto ou vivo o patrimônio fornece o húmus a terra fértil necessária ao desenvolvimento. Desenvolvimento que não se faz fora do solo, suas raízes devem se nutrir de numerosos materiais presentes no patrimônio; o solo, a paisagem, a memória os modos de vida dos habitantes, das construções e etc.

Como em todo fenômeno de crescimento e vida haverá destruição, perdas, aparição de novos objetos novas formas de vida $A$ natureza e a cultura são vivas, enquanto pertencem a sua população. Assim como uma planta morre se retirada do solo, assim é o patrimônio arrancado de sua comunidade, devendo ser cultivado, herdado transformado produzido e transmitido de geração a geração.

\section{A NECESSIDADE DE MEMÓRIA E HISTÓRIA, A PROBLEMÁTICA NECESSÁRIA}

As Comunidades Remanescentes são exemplos de resistência e luta de valores culturais, esses permanecem vivos na memória dos habitantes, e se expressam através da oralidade. Depreende-se que a relação entre história e memória pode ser descrita como tensa e inevitável fundamental, porém fundamental. Tal discussão se faz necessária ao nos depararmos com as discussões de Patrimônio como de comunidades tradicionais, ambos embelecidos nestes complexos conceitos.

Ao longo da década de 80, aumentou se o interesse pela questão da memória, os estudos se disseminaram em várias disciplinas e campos discursivos, como linguística, filosofia da história. Acrescenta se ainda a relevância do tema em expansão tanto na prática de instituições culturais quanto na mídia, isto se deve à constantes transformações das novas tecnologias de informação, pela mídia e pelo imediatismo e individualismo, que conduzem a sociedade a uma instabilidade, buscando na memória ressignificações afetivas para as sociedades onde encontramos também as discussões sobre Patrimônio. Assim se faz necessário nos debruçar sobre a complexidade em torno destes conceitos tão caros ao no trabalho.

Nora (1992) em Entre memória e história: a problemática dos lugares, memória e história, longe de serem sinônimos, nos dão consciência que tudo opõe uma, à outra. Para o autor, a memória é um processo vivido, conduzido por grupos vivos, portanto, em evolução permanente e suscetível a todas as manipulações A memória é vida, sempre carregada por grupos vivos e, nesse sentido, ela está em permanente evolução, aberta à dialética da lembrança e do esquecimento, inconsciente de suas deformações sucessivas, vulnerável a todos os usos e manipulações, susceptível de longas latências e de repentinas revitalizações. Em contrapartida, a história é um registro, um distanciamento pautado na problematização, crítica e reflexão. Os grupos de memória povoam suas lembranças, repetindo religiosamente aquilo que é e sempre foi (tradição). A história, como operação intelectual, 
dessacraliza a memória. "A história é reconstrução sempre problemática e incompleta do que não existe mais" uma operação intelectual e laicizante. A memória se enraíza no concreto, no espaço, no gesto, na imagem, no objeto a história só se liga às continuidades temporais, às evoluções e às relações das coisas. A memória é um absoluto e a história só conhece o relativo ${ }^{11}$.

Tal ideia vai de encontro ao argumento de Le Goff (1994), no qual afirma: o que sobrevive afinal não é o conjunto daquilo que existiu no passado, mas uma escolha, esta por sua vez feita por forças que operam no desenvolvimento temporal do mundo e da humanidade, escolhas que se cristalizam nos materiais da memória: os monumentos, herança do passado, e os documentos, escolha do historiador.

Impossível discutir História e memória sem fazer menção aos termos cunhados por Halbswachs (2005) em seu Livro Memória Coletiva: "memória coletiva", "memória individual" e "memória histórica". O elemento chave de sua discussão de seu livro estaria na ideia de que a memória individual se consolida e se mantém através das interações dentro de cada grupo social, ou seja, a Memória é sempre construída em grupo, mas é também sempre um trabalho do sujeito, do indivíduo. Segundo a teoria de Halbswachs (2005) seria impossível uma memória estritamente individual, ao passo que ela está formada a partir de grupos de referência, assim segundo esta concepção o conceito de Memória individual pode ser entendido como um ponto de convergência de diferentes influências sociais e como uma forma pessoal, única de articulação das mesmas. Por sua vez a memória coletiva seria um trabalho de um grupo social realiza articulando e localizando Lembranças em quadros sociais comuns, o que resulta numa espécie de acervo de lembranças compartilhadas que integram a memória coletiva. Esta estaria ligada a tradição, pois transformaria os fatos do passado em imagens e ideias sem rupturas. Enfatiza ainda o papel de lugares e objetos para evocar as lembranças. Algumas recordações só ressurgem quando estamos fisicamente diante desses lugares e objetos, o que nos retoma as ideias de Nora (NORA, 1993).

Para além dos conceitos de memória individual ou coletiva, podemos classificar a memória de outra forma: pessoal e a outra social; ou ainda, memória autobiográfica e memória histórica. A primeira delas receberia uma ajuda da segunda, já que a nossa história pessoal também faz parte da história em geral. Esta última seria bem mais extensa, representando para nós o passado de forma resumida e esquemática, enquanto a memória de nossa vida nos apresentaria do passado um panorama mais denso e contínuo.

Segundo Halbwachs (2005), nossa memória se apega mais ao fato vivido do que aquele que entremos em contato através dos livros. A menos que tenha alguma relação dinâmica com o tempo vivido, a história se assemelha para o autor como uma espécie de cemitério, tão pobre e vazio de sentido como as inscrições nas lápides dos túmulos e onde se estaria o tempo todo procurando espaço para novas sepulturas.

Seguindo a linha de pensamento de Halbswachs (memória como processo coletivo e social), temos Michael Pollak (1989) em seu livro Memória, Esquecimento, Silêncio. Tomando inicialmente o conceito de memória coletiva, o autor faz uma espécie de análise de diferentes processos e sujeitos, que interferem na formalização das memórias. Trazendo para a discussão novos conceitos como memórias subterrâneas e memórias clandestinas. Reforça desde o primeiro instante a relação entre

11 NORA, Pierre. Entre memória e história: a problemática dos lugares. Projeto História, São Paulo (10), dez. 1993, p 9. 
memória e identidade de um Grupo social; "uma memória também que, ao definir o que é comum a um grupo o diferencia dos outros, fundamenta e reforça os sentimentos de pertencimento e as fronteiras socioculturais"(POLLAK, 1889). Em seus argumentos denota que a memória é: seletiva, uma construção elemento da identidade de um povo como um campo de disputas. Onde a memória dos grupos minoritários, excluídos e dominados caem no esquecimento, no silêncio.

O silêncio sobre o passado não é um esquecimento, mas é a resistência que uma sociedade civil impotente opõe ao excesso de discursos oficiais, dos grupos majoritários e dominantes.

\section{CONSIDERAÇÕES FINAIS}

A partir do momento em que debruçamos a reflexão da complexidade Memória e suas relações com a História e o patrimônio, compreendemos cada vez mais como estes estão subjulgados na sociedade na trama das Escolhas, e do quão necessário o ato de reflexão que culmina em uma ação endógena na comunidade, é necessária para desarticular as narrativas padronizadoras do que é que Patrimônio ou não, do que é História ou não ,do que deve ser lembrado e o que deve ser esquecido.

Nosso papel como Historiadores, pesquisadores do patrimônio e instituições é o de sensibilizar, facilitar educar, por em contato o conhecimento, mediatizar gerir pela margem em função do interesse geral dos cidadãos comuns, aqueles que são os detentores do patrimônio e de suas memórias. Nosso trabalho foi uma reflexão, entre conceitos e questões em torno das discussões que envolvem o patrimônio cultural de comunidades quilombolas no país, expondo um trabalho inicial e em andamento na comunidade do Buieié em Viçosa MG, apontando uma tentativa para driblar a rotina em que estas comunidades são feitas de trampolim de interesses das instituições públicas que gerem a memória movido pelo interesse econômico. Nossa contribuição está na reflexão instigando novas propostas desta mesma natureza, para que também não sejam apenas pensadas, mas também executadas.

Estas discussões trarão contribuições para analisarmos e compreendermos como se constituiu a história desta comunidade de remanescentes de quilombo, como é trabalhada a acepção desta memória pelos moradores da comunidade Buieié? Como os setores públicos e políticos da sociedade Viçosense trabalham e respaldam essa memória? Observamos a emergência de um discurso conflituoso onde a importância de um patrimônio imaterial se depara com a falta de direitos básicos de sobrevivência, o que Marshall (1967) delimita como cidadania social. Como deve se implantar ações educativas voltadas para o trabalho com a memória e o patrimônio cultural na comunidade Quilombola do Buieié? Ao passo que compreendemos que a apropriação da memória é indispensável para o fortalecimento dos sentimentos de identidade, como ancora na busca pelos e os novos tipos de cidadania. Estes são alguns dos questionamentos feitos ao decorrer deste trabalho, que somente serão respondidas através de um trabalho de reflexão e dialogo a ser realizado em juntamente aos moradores da comunidade.

Muitas destas questões ficarão como sugestões á futuros trabalhos que acreditam que a valorização e reconhecimento da memória é essencial como direito a ser parte de uma comunidade, uma cidade um território e como artifício para alçarmos direitos básicos de vida. Acreditamos que nossa maior contribuição se fará na tentativa de na prática encontrar alternativas que vislumbrem a 
memória da comunidade do Buieié tão importante quanto outras estabelecidas institucionalmente na cidade de Viçosa.

\section{REFERÊNCIAS}

ABREU, Mauricio de Almeida Escritos sobre espaço e história organização Fania Fridman, Rogério Haesbaert. Rio de Janeiro: Garamond, 2014.

ÁVILA, Cristiane Bartz de. Entre esquecimentos e silêncios: Manuel Padeiro e a memória da escravidão no Distrito de Quilombo, Pelotas, RS. 2014. 183f. (Mestrado em Memória Social e Patrimônio Cultural), Instituto de Ciências Humanas, Universidade Federal de Pelotas, Pelotas, 2014. Disponível em: http://wp.ufpel.edu.br/ppgmp/files/2016/11/Cristiane-Bartz.pdf Acesso em 21 de junho de 2017.

ARRUTI, José Maurício. Mocambo: antropologia e história do processo de formação quilombola. Bauru, SP: EDUSC, 2006

BRASIL. Constituição (1988). Brasília: Senado Federal,1988.

BRASIL. Decreto n. 4887, de 20 de novembro de 2003. Regulamenta o procedimento para identificação, reconhecimento, delimitação, demarcação e titulação das terras ocupadas por remanescentes das comunidades dos quilombos de que trata o art. 68 do Ato das Disposições Constitucionais Transitórias. Brasília, DF, 2003. Disponível em: <http://www.planalto.gov.br/ccivil_03/decreto/2003/d4887.htm>. Acesso em: 6 nov. 2013.Brasília, 1998.

BORTOLOTTO, Chiara. A salvaguarda do patrimônio cultural imaterial na implementação da Convenção da UNESCO de 2003 Revista Memória em Rede, Pelotas (RS), vol. 2, no. 4, p. 717, dez. 2010-mar. 2011.

CHUVA, Márcia Os arquitetos da memória: sociogênese das práticas de preservação do patrimônio cultural no Brasil (anos 1930-1940). Rio de Janeiro: Ed. da UFRJ, 2009.

COSTA, Fernando Em distantes paragens: demografia, riqueza, escravidão e mercado em Santa Rita do Turvo na segunda metade do oitocentos. Tese de Doutoramento apresentada ao Programa de Pós-graduação em História Econômica na USP. 2015.Acesso em dezembro de 2016.

GONÇALVES, José Reginaldo Santos. A Retórica da Perda: os discursos do patrimônio cultural no Brasil. Rio de Janeiro: Editora UFRJ; IPHAN, 1996.

HALBWACHS, Maurice. A memória coletiva. São Paulo: Editora Centauro, 2005.

INSTITUTO DO PATRIMÔNIO HISTÓRICO E ARTÍSTICO NACIONAL. Parecer 47/98 - DEPROT.

HUYSSEN, Andreas. SEDUZIDOS PELA MEMÓRIA: arquitetura, monumentos, mídia. Huyssen. Rio de Janeiro: Aeroplano, 2000.

LE GOFF, Jacques. Documento/Monumento. In: História e Memória. Trad. de Irene Ferreira e outros. 3. Ed. Campinas (SP): Editora da UNICAMP, 1994. P. 535-553.

MARSHALL, T. H. Cidadania e classe social. In: Cidadania, classe social e status. Rio de Janeiro: Zahar, s.d.1967 p. 57- 114.

MAGNO, Lucas. Que lugar é esse? Identidades e significados territoriais no bairro rural Buieié Viçosa, MG. Disponível em: <http://www.foxitsoftware.com>. Acesso em: 08 de out de 2016. 
MENESES, Ulpiano T. Bezerra de. A História, Cativa da Memória? Para um mapeamento da memória no campo das Ciências Sociais. Revista do Instituto de Estudos Brasileiros, São Paulo, n.34, 1992, p.9-23

NORA, Pierre. Entre memória e história: a problemática dos lugares. Projeto História, São Paulo (10), dez. 1993, p.7-28

POLLAK, Michael. Memória, Esquecimento, Silêncio. IN: Estudos Históricos, Rio de Janeiro, vol. 2, n. 3, 1989, p. 3-15.

PINTO, Neide Maria de Almeida. Família, identidade e vínculos no meio rural: a comunidade negra do Buieié, MG. Disponível em:< http://www.xxcbed.ufc.br/args/public/t 18.pdf >. Acesso em: 08 de out de 2016.

RICOEUR, Paul. Memória pessoal, memória coletiva. IN RICOEUR, Paul. A memória, história, o esquecimento. Campinas: Editora da Unicamp, 2007, p. 105-150

SANT'ANNA, Márcia. Escravidão no Brasil: os terreiros de candomblé e a resistência cultural dos povos negros. Disponível em: <http://portal.IPHAN.gov.br/montarDetalheConteudo.do;jsessionid=1D0B5C9E5EE39C9B517 9AFD304A4C3E9?id=12728\&sigla=Institucional\&retorno=detalhelnstitucionl>. Acesso em: 17 abr. 2012.

THOMPSON, Paul. A voz do passado. História Oral. Rio de Janeiro: Paz e Terra, 1992. 388 p.

VARINE, Hugues de. As raízes do futuro: o patrimônio a serviço do desenvolvimento local. Tradução de Maria de Lourdes Parreiras Horta. Porto Alegre: Medianiz, 2012.

VELHO, Gilberto. Patrimônio, negociação e conflito. Mana, v. 12, n.1, p. 237-248, 2006. Disponível em: <http://www.scielo.br/pdf/mana/v12n1/a09v12n1.pdf>. Acesso em: 7 nov. 2013. 